\title{
Low serum concentrations of 25-hydroxyvitamin D in children and adolescents with systemic lupus erythematosus
}

\author{
O.A.B. Peracchi ${ }^{1}$, M.T.R.A. Terreri ${ }^{2}$, R.V. Munekata ${ }^{1}$, C.A. Len $^{2}$, R.O.S. Sarni ${ }^{1}$, \\ M. Lazaretti-Castro ${ }^{3}$ and M.O.E. Hilário ${ }^{1}$ \\ ${ }^{1}$ Departamento de Pediatria, Universidade Federal de São Paulo, São Paulo, SP, Brasil \\ ${ }^{2}$ Unidade de Reumatologia Pediátrica, Departamento de Pediatria, Universidade Federal de São Paulo, São Paulo, SP, Brasil \\ ${ }^{3}$ Divisão de Endocrinologia, Departamento de Medicina, Universidade Federal de São Paulo, São Paulo, SP, Brasil
}

\begin{abstract}
We evaluated the concentrations of 25-hydroxyvitamin $\mathrm{D}[25(\mathrm{OH}) \mathrm{D}]$ in children and adolescents with juvenile systemic lupus erythematosus (JSLE) and associated them with disease duration and activity, use of medication (chloroquine and glucocorticoids), vitamin D intake, calcium and alkaline phosphatase levels, and bone mineral density. Thirty patients with JSLE were evaluated and compared to 30 healthy individuals, who were age and gender matched. Assessment was performed of clinical status, disease activity, anthropometry, laboratory markers, and bone mineral density. The 30 patients included 25 $(83.3 \%)$ females and 16 (53.3\%) Caucasians, with a mean age of 13.7 years. The mean age at diagnosis was 10.5 years and mean disease duration was 3.4 years. Mean levels of calcium, albumin, and alkaline phosphatase were significantly lower in patients with JSLE compared with controls $(\mathrm{P}<0.001, \mathrm{P}=0.006$, and $\mathrm{P}<0.001$, respectively). Twenty-nine patients (97\%) and 23 controls $(77 \%)$ had $25(\mathrm{OH}) \mathrm{D}$ concentrations lower than $32 \mathrm{ng} / \mathrm{mL}$, with significant differences between them $(\mathrm{P}<0.001)$. Fifteen patients $(50 \%)$ had vitamin D levels $<20 \mathrm{ng} / \mathrm{mL}$ and 14 had vitamin D levels between 20 and $32 \mathrm{ng} / \mathrm{mL}$. However, these values were not associated with greater disease activity, higher levels of parathormone, medication intake, or bone mineral density. Vitamin D concentrations were similar with regard to ethnic group, body mass index, height for age, and pubertal stage. Significantly more frequently than in controls, we observed insufficient serum concentrations of $25(\mathrm{OH}) \mathrm{D}$ in patients with JSLE; however, we did not observe any association with disease activity, higher levels of parathormone, lower levels of alkaline phosphatase, use of medications, or bone mineral density alterations.
\end{abstract}

Key words: Juvenile systemic lupus erythematosus; Vitamin D; Calcium; Bone metabolism; Parathormone

\section{Introduction}

Vitamin $D$ is the common denominator of a group of steroids involved in the metabolism of a variety of tissues and body systems. Its classical role is the regulation of calcium homeostasis and bone formation and reabsorption through interaction with the parathyroid glands, kidneys, and intestine (1). Over the past few years, identification of $1 \alpha$-hydroxylase and $24 \alpha$-hydroxylase, responsible for the production of 1,25-dihydroxycholecalciferol $\left[1,25(\mathrm{OH})_{2} \mathrm{D}\right]$, and the vitamin $\mathrm{D}$ receptors in the cells for innate immunity highlighted the importance of this micronutrient in immune regulation (2).

Vitamin D immunomodulatory effects are suppression of adaptative immunity through a reduction in the production of interleukin (IL)-2, gamma interferon, and tumor necrosis factor, inhibition of expression of IL-6, secretion and production of autoantibodies by B lymphocytes, and activation of innate immunity (3-6).

Epidemiological findings indicate that low 25-hydroxyvitamin D [25(OH)D] serum concentrations are associated with the development of various diseases, especially autoimmune diseases, including insulin-dependent diabetes mellitus, multiple sclerosis, rheumatoid arthritis, systemic lupus erythematosus (SLE), and inflammatory bowel disease $(5,6)$. Recent studies have confirmed that most adult patients (7-11) and children and adolescents with SLE have insufficient or deficient vitamin D concentrations associated with disease activity (12).

The aim of this study was to evaluate the concentrations of 25(OH)D in children and adolescents with juvenile SLE (JSLE) and to associate them with disease duration

Correspondence: M.T.R.A. Terreri, Rua Ipê, 112/111, 04022-005 São Paulo, SP, Brasil. Fax: +55-11-5579-1590. E-mail: teterreri@terra.com.br 
and activity, use of medication (hydroxychloroquine and glucocorticoids), vitamin D intake, calcium and alkaline phosphatase levels, and bone mineral density.

\section{Material and Methods}

In a cross-sectional study, 30 patients with JSLE according to Hochberg criteria (13) who were monitored in the Pediatric Rheumatology outpatient clinic were evaluated during the spring of 2008. The inclusion criteria were a minimum disease duration of 6 months. Patients were excluded if they could not perform bone density measurements due to incompatible stature (1), or if they had other chronic diseases interfering with calcium, phosphorus, and vitamin D metabolism, or if they did not consent to participate in the study.

The control group consisted of 30 healthy individuals, followed in a primary medical care facility, who were gender and age (maximum difference of 6 months) matched with the patients, who were not using supplements containing vitamin D or calcium, and who had no impairment in calcium, phosphorus, or vitamin $D$ metabolism.

Demographic, clinical, and treatment data were collected from the patient charts from the visit closest to the laboratory exams. The data for disease activity and medications were also recorded. Anthropometric assessment involved weight and height measurements, using the reference proposed by the World Health Organization (WHO) $(14,15)$. Pubertal development was determined as recommended by Marshall and Tanner (16).

Assessment of JSLE disease activity was performed using the SLE Disease Activity Index 2000 (SLEDAI-2K) (17). Disease activity was arbitrarily defined as SLEDAI$2 \mathrm{~K}>1$ and $>4$.

Blood samples from the patients and controls were collected in the morning after a 12-h fast for the following tests: $25(\mathrm{OH}) \mathrm{D}$, parathormone $(\mathrm{PTH})$, serum calcium, serum phosphorus, alkaline phosphatase, serum albumin, serum urea, and serum creatinine. The patients were also tested for ionized calcium, creatinine clearance, calciuria and creatinuria in an isolated sample. The calciuria and creatinuria ratio was considered abnormal if $>0.2$.

The concentration of $25(\mathrm{OH}) \mathrm{D}$ was measured by electrochemiluminescence immunoassay using the commercial kit Elecsys 25(OH)D3 assay (Modular Roche, Brazil), and intact PTH was measured by immunofluorimetric assay in 2009. The reference values for $25(\mathrm{OH}) \mathrm{D}$ were as follows: $<20 \mathrm{ng} / \mathrm{mL}$ as deficiency, between 20 and $32 \mathrm{ng} / \mathrm{mL}$ as insufficiency, and $>32 \mathrm{ng} / \mathrm{mL}$ as normal (18). For PTH the normal range was from 15 to $65 \mathrm{pg} / \mathrm{mL}$.

Serum phosphorus, serum calcium, serum urea, serum albumin, isolated calciuria, creatinuria, and creatinine clearance were measured by colorimetric analysis (Modular Roche, Brazil), serum alkaline phosphatase was measured by an enzyme activity method, and ionized calcium was measured using a potentiometer.

Bone mineral density of the spine (L1-L4) was measured by dual energy $X$-ray absorptiometry (DXA) using a LUNAR ${ }^{\text {TM }}$ DPX-MD plus machine (GE-Lunar Radiation Corporation, USA) equipped with pediatric software (version 8.5) and adjusted to stature (19). The variation coefficient for the spine, which was checked daily according to the manufacturer's specifications, was $2 \%$.

The interval between the collection of medical records and of blood exams and the measuring of bone mineral density ranged from 0 to 90 days.

Statistical analyses were carried out with the statistical software Minitab 15 (Minitab Inc., USA). To evaluate the association between dichotomous variables, the chisquare test was applied, and, when indicated, the Fisher test was applied. The normality of continuous variables was established by means of the Kolmogorov-Smirnov test and reported as means \pm SD and the Student $t$-test was used to compare them. When both variables were symmetric, Pearson's correlation coefficient was used. A value of $\alpha<5 \%$ was adopted $(P<0.05)$.

Informed consent forms were signed by all patients and controls and/or their legal guardians. The review board of Universidade Federal de São Paulo approved the study protocol.

\section{Results}

Of the 30 children and adolescents with JSLE, 25 $(83.3 \%)$ were female, 16 were Caucasian $(53.3 \%)$, and the current mean age was 13.7 years ( $7-18$ years). The mean age at diagnosis was 10.5 years ( $3-15$ years) and the mean disease duration was 3.4 years $(0.5-12.2$ years). All patients used sunblock and avoided exposure to sunlight.

The control group consisted of 30 healthy volunteers, 25 were female (83.3\%), 16 were Caucasian (53.3\%) with a mean age of 13.6 years (6-19 years). Table 1 displays the characteristics of the groups studied.

Nineteen patients $(63 \%)$ had renal involvement at the time of diagnosis and 10 of $30(33 \%)$ had renal disease activity at the time of the evaluation. No patient had renal function impairment. The calciuria/creatinuria ratio was normal in all patients.

Mean $25(\mathrm{OH}) \mathrm{D}$ concentration in patients was significantly lower than that observed in the controls $(\mathrm{P}<0.001$; Table 2). Fifteen patients (50\%) and 6 controls (20\%) had 25(OH)D deficiency, 14 patients (47\%) and 17 controls $(57 \%)$ had $25(\mathrm{OH}) \mathrm{D}$ insufficiency, and only 1 patient $(3 \%)$ and 7 controls $(23 \%)$ had sufficient concentrations of 25(OH)D. There was no significant difference between groups regarding the mean PTH levels $(P=0.268$; Table 2).

Patients had a mean serum level of $1.29 \mathrm{mg} / \mathrm{mL}$ ionized calcium (1.21-1.35 mg/mL; within normal range), 
Table 1. Characteristics of demographics, nutritional status and pubertal stage of patients $(n=30)$ with juvenile systemic lupus erythematosus (JSLE) and controls.

\begin{tabular}{lrrr}
\hline Variables & $\begin{array}{c}\text { JSLE } \\
(\mathrm{n}=30)\end{array}$ & $\begin{array}{c}\text { Controls } \\
(\mathrm{n}=30)\end{array}$ & $\mathrm{P}$ \\
\hline Age & & & \\
$\quad$ Mean in years & 13.7 & 13.6 & $0.846^{\mathrm{a}}$ \\
$\quad$ Range & $7-18$ & $6-19$ & \\
Sex & & & \\
$\quad$ Female & $25(83.3)$ & $25(83.3)$ & $1.000^{\mathrm{b}}$ \\
$\quad$ Male & $5(16.7)$ & $5(16.7)$ & \\
Ethnicity & & & \\
$\quad$ Caucasian & $16(53.3)$ & $16(53.3)$ & $1.000^{\mathrm{b}}$ \\
$\quad$ Non-Caucasian & $14(46.7)$ & $14(46.7)$ & \\
Classification according to the BMI Z score & & & \\
$\quad$ Adequate & $17(60.7)$ & $26(89.7)$ & $0.011^{\mathrm{b}}$ \\
$\quad$ Not adequate & $11(39.3)$ & $3(10.3)$ & \\
Classification according to the H/A Z score & & & \\
$\quad$ Adequate stature & $21(75.0)$ & $29(100.0)$ & $0.004^{\mathrm{b}}$ \\
$\quad$ Low stature & $7(25.0)$ & $0(0)$ & \\
Pubertal stage & & & \\
$\quad$ Pre-puberal & $6(20.0)$ & $2(7.0)$ & $0.129^{\mathrm{b}}$ \\
$\quad$ Puberal & $24(80.0)$ & $28(93.0)$ & \\
\hline
\end{tabular}

Data are reported as number with percent in parentheses except for age. BMI: body mass index; H/A: height for age. ${ }^{a}$ Student $t$-test; ${ }^{\mathrm{b}}$ chi-square test. ${ }^{\mathrm{C}}$ Note: 2 patients and 1 control were older than 18 years, therefore they could not be assessed by $Z$ score.

Table 2. Serum concentrations of $25(\mathrm{OH}) \mathrm{D}$ and laboratory markers of patients with juvenile systemic lupus erythematosus (JSLE) and controls.

\begin{tabular}{lccc}
\hline & $\begin{array}{c}\text { JSLE } \\
(\mathrm{n}=30)\end{array}$ & $\begin{array}{c}\text { Controls } \\
(\mathrm{n}=30)\end{array}$ & $\mathrm{P}$ \\
\hline 25(OH)D (ng/mL) & $18.8 \pm 7.3$ & $27.2 \pm 6.7$ & $<0.001^{\mathrm{a}}$ \\
& $(4.6-33.0)$ & $(15.2-39.4)$ & \\
Insufficiency/deficiency (n) & 29 & 23 & $0.023^{\mathrm{b}}$ \\
Deficiency (n) & 15 & 6 & $0.015^{\mathrm{b}}$ \\
Parathormone (pg/mL) & $35.9 \pm 17.3$ & $31.3 \pm 14.4$ & $0.268^{\mathrm{a}}$ \\
& $(14.2-79.1)$ & $(15.5-74.7)$ & \\
Albumin (mg/dL) & $4.2 \pm 0.6$ & $4.5 \pm 0.3$ & $0.006^{\mathrm{a}}$ \\
& $(2.3-5.0)$ & $(3.7-5.1)$ & \\
Urea (mg/dL) & $29.5 \pm 11.2$ & $22.4 \pm 4.7$ & $0.003^{\mathrm{a}}$ \\
& $(18.0-61.0)$ & $(16.0-34.0)$ & \\
Creatinine (mg/dL) & $0.62 \pm 0.16$ & $0.80 \pm 0.15$ & $<0.001^{\mathrm{a}}$ \\
& $(0.4-1.2)$ & $(0.5-1.2)$ & \\
Calcium (mg/dL) & $9.2 \pm 0.5$ & $9.9 \pm 0.51$ & $<0.001^{\mathrm{a}}$ \\
& $(7.7-9.8)$ & $(9.0-11.0)$ & \\
Phosphorus (mg/dL) & $4.2 \pm 0.6$ & $4.3 \pm 0.7$ & $0.743^{\mathrm{a}}$ \\
& $(3.3-5.5)$ & $(2.8-6.1)$ & \\
Alkaline phosphatase (IU) & $116.6 \pm 67$ & $256.4 \pm 138.4$ & $<0.001^{\mathrm{a}}$ \\
& $(43.0-303.0)$ & $(63.0-560.0)$ & \\
\hline
\end{tabular}

Data are reported as means $\pm S D$ with range in parentheses unless otherwise indicated. ${ }^{\mathrm{a}}$ Student $t$-test; ${ }^{\mathrm{b}}$ chi-square test. 
which did not correlate with the $25(\mathrm{OH}) \mathrm{D}$ concentrations $(P=0.308)$.

Chloroquine was used by 28 patients (93\%) and glucocorticoids by $16(53 \%)$, with a mean daily dose of $0.34 \mathrm{mg} \cdot \mathrm{kg}^{-1} \cdot \mathrm{day}^{-1}\left(0.03-0.78 \mathrm{mg} \cdot \mathrm{kg}^{-1} \cdot \mathrm{day}^{-1}\right)$, mean cumulative dose of $37,370 \mathrm{mg}(1,000-149,430 \mathrm{mg})$, and a mean duration of treatment of 32 months (4-132 months). Seventeen patients $(57 \%)$ were taking calcium and $11(37 \%)$ were taking vitamin D supplements. Of these 11 patients on vitamin D supplements, 5 had deficient vitamin $D$ concentrations, 5 had insufficient concentrations, and only 1 had sufficient concentration $(\mathrm{P}=0.705)$. Only one patient with low $25(\mathrm{OH}) \mathrm{D}$ concentration had elevated PTH levels. We did not find a correlation between vitamin $\mathrm{D}$ concentration and the use of glucocorticoids, its daily and cumulative dose, and the use of chloroquine $(P=0.504 ; P=0.969 ; P=0.20$; $P=0.455$, respectively).

We did not find any association between $25(\mathrm{OH}) \mathrm{D}$ concentration ( $\geqslant 20$ and $<20$ or $\geqslant 32$ and $<32 \mathrm{ng} / \mathrm{mL}$ ) and disease activity, for SLEDAI-2K $>1 \quad(P=0.705$ and $\mathrm{P}=0.366$, respectively) or for SLEDAI-2K $>4(\mathrm{P}=0.439$ and $P=1.00$, respectively) and mean disease duration longer or shorter/equal to 25 months $(P=0.464)$.

Twelve $(40 \%)$ patients had low bone mineral density for their age. The abnormal values of DXA did not associate with lower $25(\mathrm{OH}) \mathrm{D}$ concentrations $(\geqslant 20,<20$ or $\geqslant 32$ and $<32 \mathrm{ng} / \mathrm{mL}$, with $P=0.710$ and $P=0.400$, respectively). However, there was a significant association between cumulative glucocorticoid dose and low bone mineral density $(\mathrm{P}<0.001)$.

We did not find an association between vitamin $D$ concentrations and ethnicity (Caucasian and nonCaucasian; $\mathrm{P}=0.083$ ), body mass index (BMI; $P=0.955)$, height for age ratio $(P=0.646)$, or pubertal stage $(P=0.524)$.

We observed a positive correlation between $25(\mathrm{OH}) \mathrm{D}$ concentrations and serum calcium levels $(P=0.017$ and $r=0.306)$ and serum albumin levels $(P=0.01$ and $r=0.316)$. For $P T H$, we found a trend toward an inverse correlation with vitamin $D$ concentrations $(P=0.057$ and $r=-0.247)$.

\section{Discussion}

Vitamin $D$ deficiency is often seen in patients with SLE (7-9). Wright et al. (12), when evaluating 38 individuals with JSLE, observed a high frequency of severe vitamin $D$ deficiency $(<10 \mathrm{ng} / \mathrm{mL})$, with a significant difference compared to controls. In our study, the frequency of $25(\mathrm{OH}) \mathrm{D}$ deficiency was $50 \%$, with a significant difference compared to controls. This percentage was higher than that found by Wright et al. (12) and that described in a study on adults with SLE (20).

A possible explanation for the elevated frequency of deficiency/insufficiency that we observed may be the season of sample collection, that is, spring. Although Brazil is a tropical country, sunny all year, we cannot exclude that, in the southern regions, winter and spring are colder seasons, and this population is more protected by winter clothing. Thudi et al. (21) reported $25(\mathrm{OH}) \mathrm{D}$ concentrations lower than $32 \mathrm{ng} / \mathrm{mL}$ ( $80 \mathrm{nmol} / \mathrm{L}$ ) in $65 \%$ of the SLE patients, of Hispanic-American and AfricanAmerican origin, and the values found in winter and spring were significantly lower than those in summer and fall (21).

Photosensitivity and the consequent use of sunblock, renal function impairment, presence of auto-antibodies against vitamin $\mathrm{D}$, and use of glucocorticoids are risk factors for vitamin $D$ deficiency in SLE patients $(6,22)$. For chloroquine, there is no consensus yet, and initial reports point out that it may cause possible interference to vitamin $D$ metabolism, resulting in a lowering of its concentration (23); however, a more recent study of patients with SLE found a protective effect for this vitamin deficiency (20). In our study, chloroquine was not associated with vitamin D concentration or the use of glucocorticoids. Despite vitamin D supplementation (doses of about $400 \mathrm{IU}$ ), we did not observe any benefit on the prevention of this vitamin deficiency.

There is no consensus in the literature on the ideal vitamin D concentration. Recently, Abrams (24) suggested that $25(\mathrm{OH}) \mathrm{D}$ concentrations greater than $20 \mathrm{ng} /$ $\mathrm{mL}$ would be sufficient to meet the needs of most children and adults.

Gordon et al. (25) in 2008 evaluated 365 healthy children and found $25(\mathrm{OH}) \mathrm{D}$ concentrations of $<20 \mathrm{ng} /$ $\mathrm{mL}$ in $12.1 \%$ and $<30 \mathrm{ng} / \mathrm{mL}$ in $40 \%$. In a study evaluating healthy North American children between 2001 and 2004, 9\% deficiency and 61\% insufficiency were observed, i.e., $70 \%$ of the individuals had serum concentrations lower than $32 \mathrm{ng} / \mathrm{mL}$ (26). According to Greer (27), we should define the nutritional status related to vitamin $\mathrm{D}$ based not only on $25(\mathrm{OH}) \mathrm{D}$ concentration, but also on the genetic, environmental, and dietetic factors involved with vitamin D and calcium and bone mineralization.

Despite the high frequency of 25(OH)D deficiency that we observed in JSLE patients, we did not verify a significant alteration in levels of alkaline phosphatase, PTH, or bone mineral density. The use of glucocorticoids may have lowered the alkaline phosphatase levels. Serum calcium was statistically lower in the patients compared to the controls; however, an expected hyperphosphatemia due to low calcium levels did not occur, nor did abnormal levels of ionized calcium.

In our study, we observed a direct and significant correlation between vitamin $\mathrm{D}$ concentrations and serum calcium levels. Although PTH levels did not show an inverse correlation with vitamin $\mathrm{D}$ concentration, a trend was observed. This proves that the action of PTH is often stimulated when serum calcium levels are low due to a 
decrease in vitamin $D(24,25,27)$.

Approximately one third of the patients had low bone mineral density, however, without any association with vitamin $\mathrm{D}$ concentration. Although this is an unexpected finding, we know that low bone mineral density can be influenced by other factors such as presence of inflammation and use of glucocorticoids, and those factors may explain this finding. Compeyrot-Lacassagne et al. (28) evaluated a group of 64 patients with JSLE and found that $38 \%$ had low bone mass density for their age, a result close to our findings of $40 \%$. These authors also found a significant association between cumulative glucocorticoid dose and low bone mineral density $(P<0.001)$, the same as observed in our study.

Regarding disease activity and vitamin $D$ deficiency, the current data are controversial $(11,20,29-31)$. Our sample was characterized by JSLE patients with low disease activity (mean value of SLEDAI-2K score was $4.4,63.4 \%$ of the patients with SLEDAI-2K $>1$ and $33.4 \%$ $>4$ ). Wright et al. (12) found an association between vitamin $\mathrm{D}$ deficiency and greater disease activity; however, they could not establish a causal relationship between them. Casella et al. (32) also found an association between vitamin $\mathrm{D}$ deficiency and negative effects on bone health and disease activity in a cohort of pediatric lupus patients in spite of conventional vitamin $D$ supplementation. This finding was independent of therapy and fat mass, and they suggested that those patients might need higher doses of vitamin $D$ supplementation. Kamen et al. (22) suggested that vitamin D supplementation in SLE patients may have a beneficial effect on the immune system in addition to the impact on bone metabolism. There is still no consensus in the literature on the vitamin $\mathrm{D}$ dosage to be supplemented in patients with JSLE. Kamen (33) stated in a recent review paper

\section{References}

1. Misra M, Pacaud D, Petryk A, Collett-Solberg PF, Kappy M. Vitamin $D$ deficiency in children and its management: review of current knowledge and recommendations. Pediatrics 2008; 122: 398-417, doi: 10.1542/peds.2007-1894

2. Lehmann B, Meurer M. Vitamin D metabolism. Dermatol Ther 2010; 23: 2-12, doi: 10.1111/j.1529-8019.2009. 01286.x.

3. Cantorna MT, Zhu Y, Froicu M, Wittke A. Vitamin D status, 1,25-dihydroxyvitamin D3, and the immune system. Am J Clin Nutr 2004; 80: 1717S-1720S.

4. Holick MF. Vitamin D deficiency. N Engl J Med 2007; 357: 266-281, doi: 10.1056/NEJMra070553.

5. Cutolo M, Otsa K. Review: vitamin D, immunity and lupus. Lupus 2008; 17: 6-10, doi: 10.1177/0961203307085879.

6. Arnson $Y$, Amital H, Shoenfeld $Y$. Vitamin $D$ and autoimmunity: new aetiological and therapeutic considerations. Ann Rheum Dis 2007; 66: 1137-1142, doi: 10.1136/ ard.2007.069831.

7. Marques CD, Dantas AT, Fragoso TS, Duarte AL. The that a clinical trial comparing the use of 800 to 2000 or 4000 IU of vitamin D is in progress.

In the present study, BMI and height to age ratio did not influence vitamin $D$ concentration, and, when we assessed only patients and controls with adequate weight and stature, we found a significant difference regarding their vitamin $\mathrm{D}$ concentrations.

It is well known that renal failure leads to limitations in the conversion of inactive to active forms of vitamin D; however, we did not observe renal impairment in any patient, and this has not been an aggravating factor in vitamin $\mathrm{D}$ concentrations $(1,34)$.

Regarding ethnicity, it is known that non-Caucasians usually have lower vitamin $D$ concentrations due to limitations in vitamin $D$ production from solar exposure in those individuals; however, we did not find a statistical difference between the two races (1). This finding is controversial, since our study population had a high mixture of ethnicities, which hampered a precise classification.

There are some limitations in the present study, such as the small sample size, the cross-sectional model used which does not allow causal evaluations, and the lack of DXA in the control group. Also, the method applied in the determination of 25(OH)D concentrations may be questioned, as well as the values considered normal.

Finally, according to our findings, JSLE patients had serum vitamin $D$ concentrations significantly lower than controls, without being associated with greater disease activity, higher levels of $\mathrm{PTH}$, or lower bone mineral density.

\section{Acknowledgments}

Research supported by FAPESP (\#2008/57420-3). importance of vitamin $D$ levels in autoimmune diseases Rev Bras Reumatol 2010; 50: 67-80, doi: 10.1590/S048250042010000100007.

8. Toloza SM, Cole DE, Gladman DD, Ibanez D, Urowitz MB. Vitamin D insufficiency in a large female SLE cohort. Lupus 2010; 19: 13-19, doi: 10.1177/0961203309345775.

9. Amital H, Szekanecz Z, Szucs G, Danko K, Nagy E, Csepany $\mathrm{T}$, et al. Serum concentrations of $25-\mathrm{OH}$ vitamin $\mathrm{D}$ in patients with systemic lupus erythematosus (SLE) are inversely related to disease activity: is it time to routinely supplement patients with SLE with vitamin D? Ann Rheum Dis 2010; 69: 1155-1157, doi: 10.1136/ard.2009.120329.

10. Ben-Zvi I, Aranow C, Mackay M, Stanevsky A, Kamen DL, Marinescu LM, et al. The impact of vitamin D on dendritic cell function in patients with systemic lupus erythematosus. PLoS One 2010; 5: e9193, doi: 10.1371/journal.pone. 0009193

11. Borba VZ, Vieira JG, Kasamatsu T, Radominski SC, Sato $\mathrm{EI}$, Lazaretti-Castro M. Vitamin D deficiency in patients with 
active systemic lupus erythematosus. Osteoporos Int 2009; 20: 427-433, doi: 10.1007/s00198-008-0676-1.

12. Wright TB, Shults J, Leonard MB, Zemel BS, Burnham JM. Hypovitaminosis $D$ is associated with greater body mass index and disease activity in pediatric systemic lupus erythematosus. J Pediatr 2009; 155: 260-265, doi: 10. 1016/j.jpeds.2009.02.033.

13. Hochberg MC. Updating the American College of Rheumatology revised criteria for the classification of systemic lupus erythematosus. Arthritis Rheum 1997; 40: 1725, doi: 10.1002/art.1780400928.

14. WHO. Physical status: the use and interpretation of anthropometry. Geneva: Report of a WHO Expert Committee. Report No. 854; 1995.

15. de Onis M, Onyango AW, Borghi E, Siyam A, Nishida C, Siekmann J. Development of a WHO growth reference for school-aged children and adolescents. Bull World Health Organ 2007; 85: 660-667, doi: 10.2471/BLT.07.043497.

16. Marshall WA, Tanner JM. Variations in pattern of pubertal changes in girls. Arch Dis Child 1969; 44: 291-303, doi: 10.1136/adc.44.235.291.

17. Gladman DD, Ibanez D, Urowitz MB. Systemic lupus erythematosus disease activity index 2000. J Rheumatol 2002; 29: 288-291.

18. Grant WB, Holick MF. Benefits and requirements of vitamin D for optimal health: a review. Altern Med Rev 2005; 10: 94111.

19. Khan AA, Bachrach L, Brown JP, Hanley DA, Josse RG, Kendler DL, et al. Standards and guidelines for performing central dual-energy $\mathrm{x}$-ray absorptiometry in premenopausal women, men, and children. J Clin Densitom 2004; 7: 51-64, doi: 10.1385/JCD:7:1:51.

20. Ruiz-Irastorza G, Egurbide MV, Olivares N, MartinezBerriotxoa A, Aguirre C. Vitamin D deficiency in systemic lupus erythematosus: prevalence, predictors and clinical consequences. Rheumatology (Oxford) 2008; 47: 920-923, doi: 10.1093/rheumatology/ken121.

21. Thudi A, Yin S, Wandstrat AE, Li QZ, Olsen NJ. Vitamin D levels and disease status in Texas patients with systemic lupus erythematosus. Am J Med Sci 2008; 335: 99-104, doi: 10.1097/MAJ.0b013e318134eeb6.

22. Kamen DL, Cooper GS, Bouali H, Shaftman SR, Hollis BW, Gilkeson GS. Vitamin D deficiency in systemic lupus erythematosus. Autoimmun Rev 2006; 5: 114-117, doi: 10.1016/j.autrev.2005.05.009.

23. Huisman AM, White KP, Algra A, Harth M, Vieth R, Jacobs
$\mathrm{JW}$, et al. Vitamin D levels in women with systemic lupus erythematosus and fibromyalgia. J Rheumatol 2001; 28 : 2535-2539.

24. Abrams SA. Dietary guidelines for calcium and vitamin D: a new era. Pediatrics 2011; 127: 566-568, doi: 10.1542/ peds.2010-3576.

25. Gordon CM, Feldman HA, Sinclair L, Williams AL, Kleinman PK, Perez-Rossello J, et al. Prevalence of vitamin D deficiency among healthy infants and toddlers. Arch Pediatr Adolesc Med 2008; 162: 505-512, doi: 10.1001/ archpedi.162.6.505

26. Kumar J, Muntner P, Kaskel FJ, Hailpern SM, Melamed ML. Prevalence and associations of 25-hydroxyvitamin $\mathrm{D}$ deficiency in US children: NHANES 2001-2004. Pediatrics 2009; 124: e362-e370, doi: 10.1542/peds.2009-0051.

27. Greer FR. Defining vitamin $D$ deficiency in children: beyond $25-\mathrm{OH}$ vitamin D serum concentrations. Pediatrics 2009; 124: 1471-1473, doi: 10.1542/peds.2009-2307.

28. Compeyrot-Lacassagne S, Tyrrell PN, Atenafu E, Doria AS Stephens D, Gilday D, et al. Prevalence and etiology of low bone mineral density in juvenile systemic lupus erythematosus. Arthritis Rheum 2007; 56: 1966-1973, doi: 10.1002/ art.22691.

29. Pelajo CF, Lopez-Benitez JM, Miller LC. Vitamin D and autoimmune rheumatologic disorders. Autoimmun Rev 2010; 9: 507-510, doi: 10.1016/j.autrev.2010.02.011.

30. Becker A, Fischer R, Schneider M. [Bone density and 25$\mathrm{OH}$ vitamin $\mathrm{D}$ serum level in patients with systemic lupus erythematosus]. Z Rheumatol 2001; 60: 352-358, doi: $10.1007 / \mathrm{s} 003930170035$

31. Muller K, Kriegbaum NJ, Baslund B, Sorensen $\mathrm{OH}$ Thymann M, Bentzen K. Vitamin D3 metabolism in patients with rheumatic diseases: low serum levels of 25-hydroxyvitamin D3 in patients with systemic lupus erythematosus. Clin Rheumatol 1995; 14: 397-400, doi: 10.1007/ BF02207671.

32. Casella CB, Seguro LP, Takayama L, Medeiros D, Bonfa E, Pereira RM. Juvenile onset systemic lupus erythematosus: a possible role for vitamin $D$ in disease status and bone health. Lupus 2012; 21: 1335-1342, doi: 10.1177/ 0961203312454929.

33. Kamen DL. Vitamin D in lupus - new kid on the block? Bull NYU Hosp Jt Dis 2010; 68: 218-222.

34. DeLuca HF. Overview of general physiologic features and functions of vitamin D. Am J Clin Nutr 2004; 80: 1689S$1696 S$. 